\title{
25-Hydroxycholecalciferol status in plasma is linearly correlated to daily summer pasture time in cattle at $56^{\circ} \mathrm{N}$
}

\author{
Lone Hymøller* and Søren K. Jensen \\ Department of Animal Science, Aarhus University, Blichers Allé 20, Box 50, DK-8830 Tjele, Denmark \\ (Submitted 17 June 2011 - Final revision received 4 October 2011 - Accepted 5 October 2011 - First published online 6 February 2012)
}

\begin{abstract}
In vitro studies with skin samples or pure precursors of cholecalciferol indicated that cholecalciferol synthesis during UV light exposure is a non-linear process. However, in vitro studies indicate nothing about the relationship between sunlight exposure and physiological cholecalciferol status of living organisms. Due to the lack of cholecalciferol in plant material, this relationship is important for herbivores including domestic cattle, particularly in organic agriculture, because the use of synthetic additives, like cholecalciferol, is restricted in order to fulfil the principles of sustainable organic production. The major physiological metabolite of cholecalciferol is the liver-derived 25-hydroxycholecalciferol $\left(25(\mathrm{OH}) \mathrm{D}_{3}\right)$. The purpose of the present study was to determine the relationship between sunlight exposure and $25(\mathrm{OH}) \mathrm{D}_{3}$ status in vivo in large herbivores during mid-summer at $56^{\circ} \mathrm{N}$. Five groups of cows were given access to pasture during $15,30,75,150$ or 300 min daily for $28 \mathrm{~d}$ in June and plasma analysed for $25(\mathrm{OH}) \mathrm{D}_{3}$. Animals allowed 15,30 or 75 min of daily access to pasture showed a declining linear relationship between plasma $25(\mathrm{OH}) \mathrm{D}_{3}$ and sampling day in contrast to animals allowed 150 or $300 \mathrm{~min}$ of pasture access which showed linear increasing plasma $25(\mathrm{OH}) \mathrm{D}_{3}$ status. Determined from the slopes of $25(\mathrm{OH}) \mathrm{D}_{3} \mathrm{concen}-$ tration curves within treatments, breakeven for maintaining the initial $25(\mathrm{OH}) \mathrm{D}_{3}$ status of $45 \mathrm{nmol} / 1$ was 90 min pasture access per $\mathrm{d}$ during summer at $56^{\circ} \mathrm{N}$.
\end{abstract}

Key words: Cholecalciferol: 25-Hydroxycholecalciferol: Sunlight exposure: Endogenous synthesis: Cattle

The only source of cholecalciferol (vitamin $\mathrm{D}_{3}, \mathrm{D}_{3}$ ) in grazing herbivores is endogenous $D_{3}$ produced in the skin during exposure to UV light from sunlight, since common grassland plants do not contain $D_{3}$. Endogenous $D_{3}$ is derived from 7-dehydrocholesterol (7DHC) produced in epithelial cells from acetate through the cholesterol synthesis pathway ${ }^{(1,2)}$. Irradiation with UV light between 290 and $315 \mathrm{~nm}$ cleaves the $\mathrm{C} 9$ and $\mathrm{C} 10$ bonds of $7 \mathrm{DHC}$, rendering pre-cholecalciferol $\left(\right.$ pre $\left._{3}\right)$, which as a result of its thermodynamically unstable cis-cis configuration, spontaneously isomerises into $\mathrm{D}_{3}$ by a rearrangement of its double bonds catalysed by heat at body temperature ${ }^{(2,3)}$, a process completed in $2-4 \mathrm{~d}^{(4)}$. If $\mathrm{preD}_{3}$ is exposed to excessive amounts of UV light it will, instead of being isomerised into $\mathrm{D}_{3}$, be turned into different inactive metabolites of $\mathrm{D}_{3}$ catalysed by UV light ${ }^{(3,5)}$.

Even though the biochemical and physiological processes behind endogenous $\mathrm{D}_{3}$ synthesis in the skin are well described, it is still heavily debated as to how much UV light or sunlight is necessary to secure and maintain a sufficient $\mathrm{D}_{3}$ status in plasma, measured as 25-hydroxycholecalciferol $\left(25(\mathrm{OH}) \mathrm{D}_{3}\right)$, which is the major physiological metabolite of $\mathrm{D}_{3}$ circulating in plasma and indicative of the physiological $\mathrm{D}_{3}$ status of living organisms ${ }^{(6)}$. Solar UV light intensity is affected by latitude, time of day and season; and Engelsen et $a l{ }^{(7)}$ showed that cutaneous $\mathrm{D}_{3}$ synthesis could not be sustained throughout the year at latitudes higher than $50^{\circ}$. In addition, clouds, aerosols and thick ozone events reduce the duration of $\mathrm{D}_{3}$ synthesis and can induce a 'vitamin $\mathrm{D}$ winter' even at the equator ${ }^{(7)}$.

In studies on rat and pig skin subjected to UV light, between 15 and $30 \%$ of the $7 \mathrm{DHC}$ present in the skin samples was turned into $\mathrm{D}_{3}$, resulting in a total endogenous production of $\mathrm{D}_{3}$ between 0.125 and $0.375 \mu \mathrm{g} / \mathrm{cm}^{2}$ in rat skin and between 0.75 and $2.25 \mu \mathrm{g} / \mathrm{cm}^{2}$ in pig skin ${ }^{(8,9)}$. Studies with human skin samples, expressing varying degrees of pigmentation and exposed to different UV light intensities, showed that the formation of $\operatorname{preD}_{3}$ from $7 \mathrm{DHC}$ was non-linear and reached a plateau when $10-15 \%$ of the $7 \mathrm{DHC}$ present in the skin was photoisomerised. This was irrespective of the degree of pigmentation, but the necessary exposure time increased as pigmentation darkened ${ }^{(10,11)}$. An in vitro method, utilising the exposure of solutions of pure 7DHC in ethanol to UV light

Abbreviations: $25(\mathrm{OH}) \mathrm{D}_{3}$, 25-hydroxycholecalciferol; 7DHC, 7-dehydrocholesterol; $\mathrm{D}_{3}$, vitamin $\mathrm{D}_{3}$; preD 3 , pre-cholecalciferol.

*Corresponding author: L. Hymøller, email lone.hymoller@agrsci.dk 
and subsequent measurement of the amount of $\mathrm{D}_{3}$ produced, also revealed a non-linear relationship between the UV light dose given and the resulting $\mathrm{D}_{3}$ synthesis ${ }^{(6)}$.

However, none of these in vitro methods allowed for prediction of the impact of UV light or sunlight irradiation on the $25(\mathrm{OH}) \mathrm{D}_{3}$ status of living organisms. If a direct link between UV light or sunlight exposure and $25(\mathrm{OH}) \mathrm{D}_{3}$ status in plasma in vivo should be established, it would involve completely restricted access to UV light sources and sunlight during the experimental period, a diet void of $\mathrm{D}_{3}$ and a possibility for easy blood sampling. Such a study would be difficult to perform in wild herbivores. Furthermore, the relationship between sunlight exposure and the resulting $25(\mathrm{OH}) \mathrm{D}_{3}$ status is of interest to both wild herbivores and domestic livestock reared outside; especially livestock in organic production, where the use of artificial feed additives, including synthetic vitamins, is restricted to fulfil the principles of sustainable organic production ${ }^{(12)}$.

Recently we showed that cows, in contrast to common notion, synthesise $\mathrm{D}_{3}$ in their entire skin surface when exposed to summer sunlight ${ }^{(13)}$. Furthermore, commercial dairy cows are easy to control with respect to $D_{3}$ supply in contrast to wild herbivores, because their daily routines vary extremely little and they do not obtain any $\mathrm{D}_{3}$ from sources other than the sun at pasture or synthetic feed additives in the barn. Hence, the present study was carried out in black and white Danish Holstein cows.

The aim of the present experiment was to investigate the necessary time-interval that large herbivores, exemplified by dairy cows, must have during access to pasture in midsummer at $56^{\circ} \mathrm{N}$ in order to maintain a constant $25(\mathrm{OH}) \mathrm{D}_{3}$ status in plasma, and to investigate the suggested non-linear relationship between sunlight exposure time and $25(\mathrm{OH}) \mathrm{D}_{3}$ status in plasma in vivo.

\section{Materials and methods}

\section{Animals and management}

The study complied with the Danish Ministry of Justice Law no. 1306 (23 November 2007) concerning experiments with animals and care of experimental animals and was under the supervision of the Danish Animal Experiments Inspectorate. A total of twenty dairy cows of black and white Danish Holstein breed in first lactation with an average yield of 27.5 (sEm 0.8) kg energy-corrected milk per $\mathrm{d}^{(14)}$ were used. The animals were divided into five treatment groups according to their daily energy-corrected milk yield and dominant coat colour (black or white), and let out for pasture daily during different time intervals at daytime. In the remaining time, the animals were housed in tie stalls without access to sunlight. In the barn, the feed consisted of an ad libitum maize- and grass clover silage-based total mixed ration without added $\mathrm{D}_{3}$. The total mixed ration was given once daily at 09.00 hours and milking was carried out twice daily at 06.00 and 17.00 hours. The study was conducted from 3 June to 30 June 2010 at the Department of Animal Science, Aarhus University in Tjele, Denmark at $9 \cdot 3^{\circ} \mathrm{E} / 56 \cdot 3^{\circ} \mathrm{N}$. Median, minimum and maximum values of global radiation in the geographical area during the study period are shown in Fig. 1. The data were obtained from the meteorological database at Aarhus University.

\section{Treatments}

Treatments consisted of five different durations of daily access to pasture: 15, 30, 75, 150 and $300 \mathrm{~min}$. Animals with $300 \mathrm{~min}$ daily access to pasture were let out at 10.45 hours followed by the other treatment groups in reverse access time order, so that all animals were at pasture at sun zenith at 13.23 hours. Then,



Fig. 1. Global radiation per hour (median, minimum and maximum values) during the time dairy cows spent at pasture each day of the study period in June 2010 at $56^{\circ} \mathrm{N}$ (data from the meteorological database at Aarhus University). 
Daily pasture time (min)

\begin{tabular}{|c|c|c|c|c|c|}
\hline \multirow[b]{2}{*}{ Time of day (hours) } & \\
\hline & 300 & 150 & 75 & 30 & 15 \\
\hline \multicolumn{6}{|c|}{ Time for letting animals out at pasture } \\
\hline \multicolumn{6}{|l|}{10.45} \\
\hline \multicolumn{6}{|l|}{12.00} \\
\hline \multicolumn{6}{|l|}{12.45} \\
\hline \multicolumn{6}{|l|}{13.15} \\
\hline \multicolumn{6}{|l|}{13.20} \\
\hline \multicolumn{6}{|c|}{ Time for animals returning to the barn } \\
\hline \multicolumn{6}{|l|}{13.35} \\
\hline \multicolumn{6}{|l|}{13.45} \\
\hline \multicolumn{6}{|l|}{14.00} \\
\hline \multicolumn{6}{|l|}{14.30} \\
\hline 15.45 & & & & & \\
\hline
\end{tabular}

Fig. 2. Study design. $\square$, Animals at pasture.

the animals returned to the barn in the opposite order in which they were let out for pasture, with animals in the 300 min treatment group returning to the barn last at 15.45 hours (Fig. 2). From the onset of the study, synthetic $\mathrm{D}_{3}$ was omitted from the total mixed feed ration used in the barn, rendering the animals with endogenous $\mathrm{D}_{3}$ from the sunlight as their only source of $\mathrm{D}_{3}$.

\section{Blood samples}

Blood was collected from the tail vein in Na-heparin-coated Vacuette ${ }^{\circledR}$ tubes (Greiner Bio-One $\mathrm{GmbH}$, Kremsmünster, Austria). Samples were collected on days 0, 1, 3, 5, 7, 9, 12, $14,16,19,21,23,26$ and 28 of the study between 08.00 and 09.00 hours, except for the day- 1 sample, which was taken



Fig. 3. Plasma concentrations of 25 -hydroxycholecalciferol $\left(25(\mathrm{OH}) \mathrm{D}_{3}\right)$ in dairy cows after daily access to pasture for different time durations in June 2010 at $56^{\circ} \mathrm{N}$

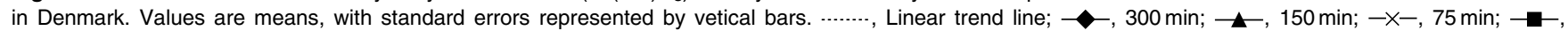
$30 \mathrm{~min} ; \multimap, 15 \mathrm{~min}$. 
Table 1. Linear equations and $R^{2}$ values of 25-hydroxycholecalciferol $\left(25(\mathrm{OH}) \mathrm{D}_{3}\right)$ plasma concentration curves (see Fig. 3) from dairy cows after daily access to pasture for different time durations in June 2010 at $56^{\circ} \mathrm{N}$ in Denmark

\begin{tabular}{lll}
\hline $\begin{array}{l}\text { Daily pasture } \\
\text { time (min) }\end{array}$ & \multicolumn{1}{c}{ Linear equation } & $R^{2}$ \\
\hline 300 & $y=1.30 x+55.6$ & 0.88 \\
150 & $y=0.31 x+49.2$ & 0.33 \\
75 & $y=-0.01 x+41.3$ & 0.002 \\
30 & $y=-0.39 x+36.8$ & 0.68 \\
15 & $y=-0.46 x+44.0$ & 0.80 \\
\hline
\end{tabular}

$x$, Daily pasture time $(\mathrm{min}) ; y$, plasma concentration of $25(\mathrm{OH}) \mathrm{D}_{3}$ $(\mathrm{nmol} / \mathrm{l})$.

at 16.00 hours after the animals returned from pasture on the first day of the study. Samples were centrifuged in a Thermo Scientific SL40 centrifuge (Thermo Scientific, Asheville, NC, USA) for $10 \mathrm{~min}$ at $1500 \mathrm{~g}$ and plasma was transferred to sample tubes (Sarstedt Group, Nümbrecht, Deutschland) and stored at $-18^{\circ} \mathrm{C}$ until analysis

\section{Chemical analysis}

In the laboratories at the Department of Animal Science, Aarhus University in Tjele, Denmark, the plasma samples were analysed for content of $25(\mathrm{OH}) \mathrm{D}_{3}$, as described by Hymøller \& Jensen ${ }^{(15)}$.

\section{Statistical analysis}

ANOVA was performed in the MIXED models procedure of SAS ${ }^{\circledR}$ (SAS Institute, Inc., Cary, NC, USA) using the model: $Y_{i j k}=\mu+\alpha_{i}+\beta_{j}+(\alpha \beta)_{i j}+C_{i j k}+\varepsilon_{i j k}$, where $Y_{i j k}$ is the plasma concentration of $25(\mathrm{OH}) \mathrm{D}_{3}, \mu$ is the overall mean, $\alpha_{i}$ is the fixed effect of $i$ minutes daily access to pasture $(15,30,75,150,300), \beta_{j}$ is the fixed effect of sampling day $j(0,1,3,5,7,9,12,14,16,19,21,23,26,28),(\alpha \beta)_{i j}$ is the effect of the interaction between $i$ minutes daily access to pasture and sampling day $j, C_{k}$ is the random effect of animal $k$ and $\varepsilon_{i j k}$ is the random residual error. To account for the covariance of repeated measures during consecutive days within animals, the covariance structure was modelled using the repeated statement of the MIXED procedure of SAS® ${ }^{(16)}$. The best model fit was obtained from the autoregressive first-order covariance structure $\left(\mathrm{AR}^{(1)}\right)$. To test for fit of a second-degree polynomial, a quadric term of $\alpha_{i}^{2}$ was added to the model; however, as the effects of the quadric term were non-significant and the model fit statistics worsened, a linear model was maintained. Because the animals were grouped according to their dominant coat colour, the effects of coat colour on the repeated measures of plasma $25(\mathrm{OH}) \mathrm{D}_{3}$ were tested by adding the fixed effect of coat colour and the interaction between coat colour and minutes of daily access to pasture to the model. Random effects were assumed normally distributed with mean value zero and constant variance $C_{i j k}$ approximately $N\left(0, \sigma_{c}^{2}\right)$ and $\varepsilon_{i j k}$ approximately $\sigma^{2}$. Results are presented as means with their standard errors and the differences considered statistically significant if $P \leq 0 \cdot 05$.

\section{Results}

The average concentration of $25(\mathrm{OH}) \mathrm{D}_{3}$ in plasma at the beginning of the study across all treatment groups was 44.9 $(\operatorname{sem} 2 \cdot 4) \mathrm{nmol} / \mathrm{l}$. At the end of the study at day 28, the $25(\mathrm{OH}) \mathrm{D}_{3}$ concentrations were: $15 \mathrm{~min}$ : $36 \cdot 2$ (sem 6.4) nmol/1, $30 \mathrm{~min}: 26.7$ (SEM 2.8 ) nmol/1, $75 \mathrm{~min}: 43.9$ (SEM 8.5) nmol/l, $150 \mathrm{~min}: \quad 67.4 \quad(\mathrm{SEM} \quad 8.6) \mathrm{nmol} / \mathrm{l}$ and $300 \mathrm{~min}: 95.9$ (SEM $6 \cdot 4) \mathrm{nmol} / \mathrm{l}$. There was a significant effect of duration of daily pasture access $(P \leq 0 \cdot 001)$ and day of sampling $(P \leq 0 \cdot 001)$, as well as a significant interaction between duration

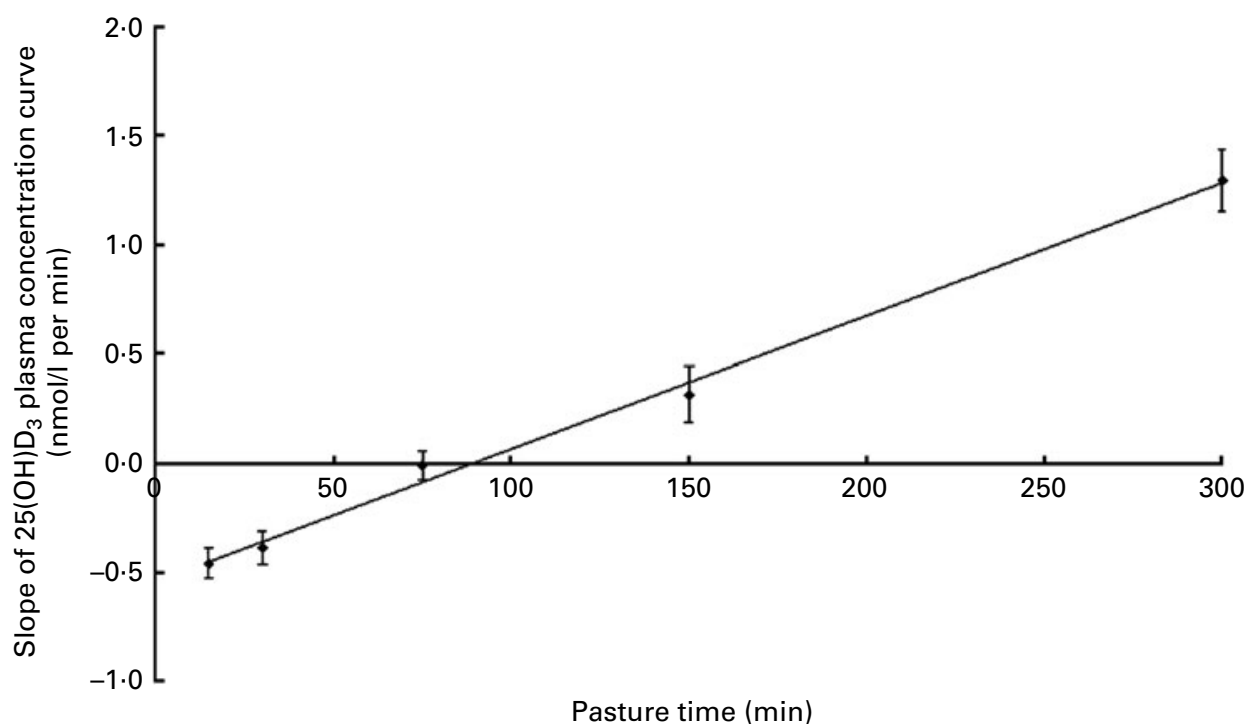

Fig. 4. Relationship between slope of linear 25-hydroxycholecalciferol $\left(25(\mathrm{OH}) \mathrm{D}_{3}\right)$ concentration curves with standard errors (see Fig. 3 ) from dairy cows and daily time spent at pasture in June 2010 at $56^{\circ} \mathrm{N}$ in Denmark (intercept with $x$-axis $90.9 \mathrm{~min}$ ). $y=0.006 x-0.545 ; R^{2} 0.995$. 
of daily pasture access and day of sampling ( $P \leq 0 \cdot 001)$. The developments in plasma concentrations of $25(\mathrm{OH}) \mathrm{D}_{3}$ within the five different treatments during the $28 \mathrm{~d}$ of study are shown in Fig. 3. Animals allowed 15, 30 or $75 \mathrm{~min}$ of daily access to pasture were unable to maintain their initial plasma status of $25(\mathrm{OH}) \mathrm{D}_{3}$ and showed a declining linear relationship between plasma $25(\mathrm{OH}) \mathrm{D}_{3}$ concentration and day of sampling in contrast to animals allowed 150 or 300 min of daily sunshine access, which showed an increasing relationship between plasma $25(\mathrm{OH}) \mathrm{D}_{3}$ and day of sampling (Fig. 3). All slopes of plasma concentration curves, except for the 75 min treatment group (slope - 0.01), were significantly different from zero in linear regression $(P \leq 0.05)$.

From the slopes of the average $25(\mathrm{OH}) \mathrm{D}_{3}$ concentration curves within treatments (Table 1), breakeven for maintaining the initial $25(\mathrm{OH}) \mathrm{D}_{3}$ status was determined to be approximately $90 \mathrm{~min}$ of pasture per $\mathrm{d}$ during mid-summer in Denmark at $56^{\circ} \mathrm{N}$ (Fig. 4). The dominant coat colour (black or white) of individual animals had no significant effect on the plasma concentrations of $25(\mathrm{OH}) \mathrm{D}_{3}$ within the different treatments.

\section{Discussion}

In cattle, the plasma status of $25(\mathrm{OH}) \mathrm{D}_{3}$ was shown by Hymøller \& Jensen ${ }^{(13)}$ to be closely related to the percentage of total skin area that was exposed to sunlight; and Barger-Lux \& Heaney ${ }^{(17)}$ showed that the size of the exposed skin area was more closely correlated to the plasma status of $25(\mathrm{OH}) \mathrm{D}_{3}$ than the duration of sunlight exposure in human subjects. In the present study, the plasma $25(\mathrm{OH}) \mathrm{D}_{3}$ status of black and white Holstein dairy cows was strongly linearly dependent on the time the animals spent at pasture on a daily basis during summer at $56^{\circ} \mathrm{N}$ in Denmark. This contradicts previous assumptions based on in vitro studies where the relationship between sunlight or UV light exposure time and the formation of $\mathrm{D}_{3}{ }^{(6)}$ and $\mathrm{preD}_{3}$ from $7 \mathrm{DHC}$ was shown to be non-linear and to reach a plateau when a fraction of the $7 \mathrm{DHC}$ present in the skin was photoisomerised ${ }^{(10,11)}$. The plateau phenomenon encountered when studying $\mathrm{D}_{3}$ synthesis during different durations of UV light exposure in vitro, with either skin samples or pure solutions of 7DHC, is probably caused by a photocatalysed degradation of the intermediate metabolite of $\mathrm{D}_{3}$, pre $\mathrm{D}_{3}$, when exposed to excessive amounts of UV light, before it had time to be isomerised into $\mathrm{D}_{3}$, catalysed by heat at body temperature ${ }^{(3,5,18)}$.

The strong linear relationship between plasma $25(\mathrm{OH}) \mathrm{D}_{3}$ and pasture time at $56^{\circ} \mathrm{N}$ in the present study could be due to non-production of inactivated metabolites of $\mathrm{D}_{3}$ in the skin. There could be different explanations supporting this: The altitude at $56^{\circ} \mathrm{N}$ could be so far north that the sunlight intensity was significantly reduced compared to lower latitudes $^{(5)}$; the hair covering the bodies of the animals could have protected their skin from direct exposure to sunlight; or the blood flow through the skin of living organisms could have transported the produced $\mathrm{D}_{3}$ away from the skin and into circulation in plasma, before it could be photodegraded by excessive sunlight exposure.
Even though it has been shown in both human subjects $^{(10,11)}$ and in fur- or hair-covered species like rats ${ }^{(19)}$ and alpacas $^{(20)}$ that dark-coloured individuals respond slower to sunlight than light-coloured individuals, no effect of dominant coat colour was found in the present study with black- and white-coloured animals.

In conclusion, our study showed that plasma concentrations of $25(\mathrm{OH}) \mathrm{D}_{3}$ were linearly correlated to day of sampling within each treatment group allowed daily access to pasture for different time intervals. Animals allowed 15, 30 or 75 min of daily access to pasture were unable to maintain their initial plasma status of $25(\mathrm{OH}) \mathrm{D}_{3}$ and showed a declining relationship between plasma $25(\mathrm{OH}) \mathrm{D}_{3}$ concentration and day of sampling in contrast to animals allowed 150 or $300 \mathrm{~min}$ of daily sunshine access, which showed an increasing relationship between plasma $25(\mathrm{OH}) \mathrm{D}_{3}$ and day of sampling. Breakeven for maintaining the initial $25(\mathrm{OH}) \mathrm{D}_{3}$ status of $45 \mathrm{nmol} / 1$ in large, hair-covered herbivores was determined to be $90 \mathrm{~min}$ of access to pasture per d during summer at $56^{\circ} \mathrm{N}$. The dominant coat colour of individual animals (black or white) had no effect on the plasma concentrations of $25(\mathrm{OH}) \mathrm{D}_{3}$.

\section{Acknowledgements}

The present work was financed by the Ministry of Food, Agriculture and Fisheries (Copenhagen, Denmark) and the Danish Cattle Federation, Knowledge Centre for Agriculture (Aarhus, Denmark). Both authors contributed equally to the data analysis and the composition of the final manuscript. The authors have no conflicts of interest with any of the founding institutions.

\section{References}

1. Gaylor JL \& Sault FM (1964) Localization and biosynthesis of 7-dehydrocholesterol in rat skin. J Lipid Res 5, 422-431.

2. Stryer L (1995) Biochemistry, 4th ed. New York, NY: W.H. Freeman and Company.

3. MacLaughlin JA, Anderson RR \& Holick MF (1982) Spectral character of sunlight modulates photosynthesis of pre-vitamin $D_{3}$ and its photoisomers in human skin. Science 216, 1001-1003.

4. McDowell LR (2000) Vitamins in Animal and Human Nutrition, 2nd ed. Ames: Iowa State University Press.

5. Webb AR, Kline L \& Holick MF (1988) Influence of season and latitude on the cutaneous synthesis of vitamin $\mathrm{D}_{3}$ : exposure to winter sunlight in Boston and Edmonton will not promote vitamin $\mathrm{D}_{3}$ synthesis in the skin. $J$ Clin Endocrinol Metab 67, 373-378.

6. Olds WJ, McKinley AR, Moore MR, et al. (2008) In vitro model of vitamin $\mathrm{D}_{3}$ (cholecalciferol) synthesis by UV radiation: dose-response relationships. $J$ Photochem Photobiol B 93, 88-93.

7. Engelsen O, Brustad M, Aksnes L, et al. (2005) Daily duration of vitamin D synthesis in human skin with relation to latitude, total ozone, altitude, ground cover, aerosols, and cloud thickness. Photochem Photobiol 81, 1287-1290.

8. Bekemeier H (1959) Versuche zur erschöpfenden UVAktivierung des Provitamins D in der Haut von Ratten, Kaninchen und Meerschweinchen (Experiments with 
exhaustive UV activation of pro-vitamin D in skin from rats, rabbits and guinea pigs). Hoppe Seyler Z Physiol Chem 314, 125-129.

9. Bekemeier H \& Pfennigsdorf G (1959) Versuche zur erschopfenden UV-Aktivierung des Provitamins D in Schweineschwarte (Experiments with exhaustive UV activation of provitamin D in pig skin). Hoppe Seyler Z Physiol Chem 314, 120-124.

10. Holick MF (1994) Vitamin D - new horizons in the 21st century. Am J Clin Nutr 60, 619-630.

11. Holick MF, MacLaughlin JA \& Doppelt SH (1981) Regulation of cutaneous pre-vitamin $\mathrm{D}_{3}$ photosynthesis in man: skin pigment is not an essential regulator. Science 211, 590-593.

12. International Federation of Organic Agriculture Movements (IFOAM) (2011) The Principles of Organic Agriculture. http://www.ifoam.org/about_ifoam/principles/index.html

13. Hymøller L \& Jensen SK (2010) Vitamin $D_{3}$ synthesis in the entire skin surface of dairy cows despite hair coverage. $J$ Dairy Sci 93, 2025-2029.

14. Sjaunja LO, Baevre L, Junkkarinen L, et al. (1991) A Nordic Proposal for An Energy Corrected Milk (ECM) Formula.
EAAP Publication 50: Performance Recording of Animals - State of the Art 1990, pp. 156-157. Wageningen: Centre for Agricultural Publishing and Documentation (PUDOC).

15. Hymøller L \& Jensen SK (2011) Vitamin D analysis in plasma by high performance liquid chromatography (HPLC) with $\mathrm{C}_{30}$ reverse phase column and UV-detection - easy and acetonitrile free. J Chromatogr A 1218, 1835-1841.

16. Littell RC, Milliken GA, Stroup WW, et al. (2006) SAS ${ }^{\circledR}$ for MIXED Models, 2nd ed. Cary, NC: SAS Institute, Inc.

17. Barger-Lux MJ \& Heaney RP (2002) Effects of above average summer sun exposure on serum 25-hydroxyvitamin D and calcium absorption. J Clin Endocrinol Metab 87, 4952-4956.

18. Webb AR, DeCosta BR \& Holick MF (1989) Sunlight regulates the cutaneous production of vitamin $\mathrm{D}_{3}$ by causing its photodegradation. J Clin Endocrinol Metab 68, 882-887.

19. Hess AF (1922) Newer aspects of the rickets problem. J Am Med Assoc 78, 1177-1183.

20. Judson GJ, McGregor BA \& Partington DL (2008) Factors associated with low vitamin D status of Australian alpacas. Austr Vet J 86, 486-490. 